\title{
LA MÚSICA: ALAS DE LA MAGIA ${ }^{1}$
}

The music: wings of magic

Bernardo González Mella Depto. Estudios Pedagógicos Universidad de Chile begonzal@u.uchile.cl

\section{LA MÚSICA: ALAS DE LA MAGIA}

La magia, la hechicería, son expresiones que nos llevan a imaginar un mundo de ritos y prácticas que pueden ser deseados o temidos; sucesos asombrosos, sin explicación, misteriosos,

"... que van desde los ritos simbólicos de los antiguos al sortilegio de la pitonisa, de la impresión en nuestro ánimo de una sinfonía a las virtudes terapéuticas de la sugestión, de la fascinación provocada por la pura belleza femenina al truco del prestidigitador... ".

Tal parece que en la naturaleza y en la vida del hombre, en toda la creación en verdad, siempre está presente un toque de encantamiento, proveniente de una dimensión mágica.

En la naturaleza se encuentra la primera forma del hechizo mágico. En este mundo de la naturaleza tienen un rol importante la luz, la música, los colores, las fragancias porque todos estos elementos actúan sobre los sentidos de los seres vivos, incitándoles sensaciones $\mathrm{y}$ anhelos.

"... El canto melodioso de los pájaros, el colorido de sus plumajes, el perfume de las flores, la secreción de substancias olorosas en ciertos animales y una serie de manifestaciones de este género, pueden clasificarse sin duda entre los innumerables medios, no todos identificables, por los cuales la naturaleza ejercita su fascinación y crea ese estado especial de encantamiento ... ".

\footnotetext{
${ }^{1}$ Publicado en VI Jornadas Interdisciplinarias. Páginas 185 - 191
} 
Así, el hombre, desde los tiempos más remotos, creó lo que podríamos llamar la magia imitativa. En su esfuerzo por lograr el encantamiento mágico imita “... el aspecto, los colores, los perfumes de los animales, los cantos de los pájaros ...”.

La música del universo, en todas sus múltiples expresiones, es la manera más antigua de percibir y de crear el "hechizo de la vida".

Pero, también, el ser humano es capaz de percibir que, junto a esta gran armonía del universo, existen las fuerzas contrarias que son las demostraciones antiestéticas de la misma naturaleza:

"... Siente el profundo temor del trueno y del relámpago, es intimidado por el violento golpear de la lluvia, aterrado ante la cruel destrucción de la vida por los torrentes de fuego que arrojan los volcanes, abrumado por los diluvios que arrasan los frutos de su trabajo en pocas horas. Percibe la intensa fascinación de las noches oscuras y sin estrellas, de los inaccesibles silencios que lo reclaman desde las profundidades de los cielos y de los mares, del encanto de la muerte. Poco a poco, lentamente, a través de los siglos escucha inconscientemente las voces de la naturaleza, va dominando las dos grandes leyes universales, las dos supremas tendencias antagónicas. ”.

Así, la fascinación de la vida y de la muerte en la naturaleza, incita al ser humano a buscar protección para su vida. En este intento de mantener alejados a los enemigos de su seguridad vital, utiliza el trueno, el fuego y todo aquello capaz de infundir terror. Pretende pactar con las fuerzas adversas ofreciéndoles ofrendas y sacrificios, verdaderos o simulados.

Cuando intenta atraer a las fuerzas benévolas, lo hace por medio de la música y a través de la imitación del canto de las aves. La fabricación de los primeros instrumentos musicales, se hace con huesos huecos; éstos proceden del paleolítico. Además, las prácticas mágicas se acompañan golpeando las palmas de las manos, o dos trozos de madera. En las batallas, por ejemplo, se cree que el tambor lleva oculto al demonio de la guerra; sin su sonido y el de las canciones de guerra, la lucha no comienza. 
"... El mago comienza el canto ... con un largo recital cantado, de las gestas gloriosas, que nos recuerda las figuras de los remotos y primitivos poetas.".

En cuanto a las características personales que debe poseer el mago, es un asunto que tiene que ver con la realidad y las necesidades de cada grupo social. Se puede decir, entonces, que el mago es una creación de su medio ambiente. La figura del mago responde únicamente a las esperanzas y a los deseos de la comunidad.

Puede ser alguien con conocimientos médicos suficientes para aliviar a las personas de sus dolencias; puede tener talento para la música, lo que le permite crear sonidos rítmicos o melodiosos, que provoquen en los individuos un estado de ánimo especial, un encantamiento. En definitiva, sabe hacer uso de todos los recursos a su alcance, para instigar a su público, admiración, miedo o fe. Porque el atributo fundamental de todo mago, es el de saber cómo inducir, en el primero, y en los demás, el estado anímico preciso y único, que es indispensable para la magia, “... el estado de encantamiento en el que se concreta y aguza su voluntad con la certeza de lograr el resultado deseado...".

En suma, la magia resulta de la forma en que se conduce la naturaleza. El encantamiento es la sensualidad cósmica, que se manifiesta en la "música del universo", en el "ritmo de sus leyes", en la belleza de sus flores, en el influjo excitante de sus perfumes, en sus juegos de luces, en las formas hermosas de sus animales, etc. Todas estas expresiones de la naturaleza componen su eterna sinfonía.

El hechizo o la fascinación que ejerce la naturaleza en el hombre, es lo que origina la magia humana.

"... Schopenhauer define la magia como la objetivación del deseo fuera de sus nexos causales, y tal vez esta fórmula sea la más evidente y comprensible de todas. Más exactamente podríamos decir: fuera de los nexos causales de los que tenemos experiencias ciertas y comprobadas."

El mago de los primeros tiempos es capaz de entender los sonidos de voces lejanas y que no pueden ser oídos por los demás. La música, los ritmos, entre otros factores, sirven para provocar en el mago y en aquellos que le rodean, el estado de encantamiento. 
En la magia primitiva ya encontramos signos de la existencia de tres elementos característicos de la magia, que se asocian a la creencia en la eficacia de los actos mágicos.

"... En primer lugar están los esfuerzos fonéticos, las imitaciones de los sonidos naturales, como el silbido del viento, el rugido del trueno, el rumor del mar, las voces de ciertas alimañas. Tales sonidos simbolizan otros tantos fenómenos y, de esta manera, se cree que los producen de modo mágico. $O$, de no ser este el caso, los tales expelen ciertos estados emotivos asociados con el deseo que ha de colmarse y cuya consecusión se lleva a cabo por medio de la magia.".

Un segundo elemento está dado por el uso de palabras, por medio de las cuales se invoca, se formula, o se ordena aquello que se desea. Por ejemplo, el hechicero o el chamán, según su propósito de sanar o matar, deberá mencionar todos los signos de la enfermedad que desea curar, o de la muerte que desea infligir.

Por último, el tercer elemento está dado por las constantes y nutridas alusiones mitológicas que están presentes en el hechizo; se hace mención de los antepasados, de los héroes de los cuales se ha recibido la sabiduría mágica.

El cuerpo humano, contenedor de los atributos mágicos, debe respetar diversas condiciones. Por ejemplo, el mago debe cuidar todo tipo de tabúes a fin de mantener incólume el hechizo:

"... en ciertas partes del mundo, por ejemplo en Melanesia, el embrujo reside en el vientre del hechicero, que es la sede del alimento y la memoria. Cuando se precise, se le hace subir a la laringe, la sede de la inteligencia, y de ésta se le envía a la voz, que es el órgano principal de la mente del hombre...".

Dentro de las prácticas mágicas y a fin de efectuar el "acto mágico, se requiere siempre de una atmósfera especia. La música, el ritmo, “... que precede y acompaña al mago en su acto, ejerce una acción excitante o deprimente sobre las facultades emotivas...”. 
Es el ritmo, que expresado a través de la música, se transforma, "en un momento o en un ambiente dado", en factor fundamental de la "acción mágica". Y junto a la música y el ritmo actúan, también como factores desencadenantes de esta acción mágica, luces de colores - combinados de manera armoniosa o chocante, dependiendo del efecto final deseado- los olores - perfumes embriagadores, por ejemplo-. Todos estos elementos sensoriales, podríamos decir -y muchos más, por cierto-, se constituyen en los activantes mágicos. Dice Arturo Castiglioni

"... La música, los ruidos, la luz son los factores mágicos que actúan a distancia para alejar a los enemigos, para ahuyentar a los poderes adversos, o para pedir la ayuda de las fuerzas amistosas, ellos son la eficaz invocación al poder que lleva el mundo mágico... ".

Los sonidos son emitidos con instrumentos o con la voz humana, lanzados con expresiones enigmáticas repetidas de manera prolongada y monótona, en un ambiente silencioso con espectadores concentrados en lo que está sucediendo. Son éstos los sonidos que llevan a los movimientos rítmicos, la danza, que en su origen posee, también, un “carácter mágico imitativo", que reproduce los gestos de los animales.

"Estos movimientos rítmicos acompañados por una música monótona, repetida una y otra vez, con una melodía triste, lenta y nostálgica, provocan en los oyentes un estado de ánimo que puede llegar a ser alucinatorio y determina la misma condición mental en los ejecutores...".

Los movimientos rítmicos, por cierto, han tenido una gran importancia a través del tiempo en todas sus variadas formas y ligados a otros factores, tales como el canto, la vestimenta, los colores, los perfumes, etc.. Castiglioni, cita como un ejemplo -muy cercano en el tiempo- la importancia que se le ha atribuido al saludo fascista, tanto en Alemania como en Italia.

La fascinante importancia de la danza, proviene de la capacidad del danzante para conseguir o simular una serie de transformaciones en su personalidad. Muchas danzas mágicas antiguas están dedicadas a la representación del ciclo de la vida y de la muerte, que 
no es otra cosa que un movimiento constante. No es extraño, entonces, que la música y la danza, sean parte de los ritos fúnebres, por ejemplo. En realidad, todo acto importante para la vida -desde los pueblos más antiguos, hasta nuestros días- fue y es acompañado por la música; está presente en la construcción de una choza o en todos los trabajos de la tierra, y muy especialmente durante la siembra y la cosecha. La danza, por su parte, conforma el preludio en todas las celebraciones de ceremonias simbólicas: las de guerras y, desde luego, en toda expresión "del hechizo de la vida y de la muerte."

El hacer uso de la música y la danza, del sonido y del ritmo, para hacer magia, es anterior al de las palabras. "El valor sugestivo de las palabras, en el ritmo más que en la significación, se ha reconocido desde los tiempos más antiguos ...”13. Y desde las épocas más remotas toda palabra, pronunciada en las prácticas mágicas, se ha emitido en forma de canto. En el Antiguo Testamento, por ejemplo, se habla del poder que tiene la música para inducir a un estado de sugestión o de frenesí:

“Llegarás después a Guibeá de Dios (donde se encuentra el gobernador de los filisteos) y a la entrada de la ciudad tropezarás con un grupo de profetas que bajan del alto, precedidos del añafil, el adufe, la flauta y la cítara, en trance profético ..." (Samuel I, Cap. 10:5)14.

"Traedme, pues, un tañedor. Y sucedió que, mientras tocaba el tañedor, vino sobre él la mano de Yahveh, ..." (Reyes II, Cap. 3:15)15.

De este modo, el mago, con su voz y con su gestualidad, expresa significaciones importantísimas para quienes participan del momento:

"... El mago canta y cuando durante el canto se exalta, se escucha su palabra como una orden o como una profecía, mientras que sus gestos adoptan una significación decisiva."16.

Es que las palabras mágicas necesitan de la música como de un medio material para poder desplazarse y crear el rito mágico: una bendición, una maldición, un exorcismo, etc... 
Con el desarrollo del pensamiento, la belleza de la forma transforma todos los gestos y los actos del ser humano; el ritmo se convierte, entonces, en melodía:

"... Podría decirse que la historia de la magia recorre los caminos seguidos por la naturaleza en la búsqueda de medios para lograr un estado de encantamiento con un propósito idéntico: exaltar la procreación..."

Paulatinamente la magia humana asume las características del arte. Así, el encantamiento adquiere formas nuevas:

"... Se origina en condiciones especiales porque su creador, el nuevo mago, se encuentra prendido, como los magos de todos los tiempos, en el hechizo que crea y ante el cual sucumbe... ".

La magia es capaz de crear "un estado de ánimo" que puede llevar más lejos de la exaltación, a un estado hipnótico, alucinatorio, de enajenación, provocado por algún tipo de elemento "tóxico"; la palabra, la música, pueden llegar a ser tremendamente efectivas, usadas en este sentido, sobre todo si existe un auditorium predispuesto. Esta sugestión, entonces, apela a las facultades emotivas. Un ejemplo de esto lo encontramos, en nuestros días, en los conciertos, tanto los de la música llamada clásica, como los de rock satánico.

La magia y el arte -el musical, en este caso- parecen íntimamente ligados en la proyección del artista-mago, podríamos decir.

Si la magia es la representación de los deseos, y hacerlos reales, concretos, por medios ocultos y sobrenaturales, capaces de dominar a los poderes superiores, se puede, entonces, hablar de la magia que está presente en toda idea artística, que lleva a cabo el encantamiento de la creación. Es posible ver y sentir en toda obra de arte aquellas características propias de la magia: la creación de un ambiente, de un mundo, singular, capaz de influir en las percepciones de quienes observan o escuchan al artista, o al mago, que proyecta su acción y logra penetrar en las mentes de quienes conforman su públicosecta. 
"... la obra de arte obra sobre las emociones individuales, directamente, a través de la sugestión y del encantamiento, y en este punto, creemos, que al igual que todas las formas de la magia, el impacto del hechizo sólo llega a su máxima pleni tud cuando la obra de arte se apodera plenamente de su creador...".

Pero, por elemental que sea el sentido musical en una sociedad, siempre se puede encontrar algún tipo de ritmo y de música que es considerada ritual. Muchas veces también, los instrumentos con los que se ejecutan los sonidos son considerados poseedores de poderes extraordinarios y mágicos, que conceden, a su vez, a sus dueños o ejecutantes, poderes sobrenaturales.

La música, desde los tiempos más remotos, ha formado parte importante de la vida de los seres humanos. Acompañándolo en sus diversiones, en sus trabajos, en sus miedos, en sus dolores, en sus esperanzas. Es un medio de alcanzar objetivos vitales: sanarse, vencer al enemigo, una caza o pesca abundante, infundirse valor, etc.

Cualquiera sea la finalidad de la música, está siempre íntimamente vinculada con un texto y/o con la danza; conformándose con estos tres elementos una totalidad, que, por lo general, funciona al unísono en el ritual mágico.

"desde las sonajas, compuestas de amuletos, las funciones rituales, el carácter simbólico o mágico no puede separarse de los instrumentos. La fertilidad, el sexo, hechos sobrehumanos están representados en ellos o son producto de su existencia. Connotaciones extramusicales se reflejan en la elección del material para construirlos."

\section{ALGUNAS REFLEXIONES FINALES}

Para terminar, podemos decir que en nuestros días la magia sigue volando en las alas de la música. El escenario de hoy son las salas de concierto, o los conciertos al aire libre. En cualquier caso, podemos encontrar allí signos de las antiguas prácticas; el mago-músico 
logra crear también un ambiente de encantamiento, en un público que, dejándose llevar por los compases, escucha muy quieto o se agita y mueve impulsado por el fuertísimo ritmo.

La fuerza de la magia-música sigue intacta, al punto que cada día más se habla de las terapias musicales, capaces de sanar todo tipo de enfermedades. Y capaces de llevarnos a un estado de éxtasis que nos permite olvidar, o soportar mejor, nuestros agobios.

Se dice que desde la Creación, ningún sonido ha dejado de repercutir en todo el universo. Será, entonces, que toda nuestra música se recompone en otros mundos lejanos y desconocidos. Y, por cierto, es muy posible, también, que parte de nuestra música nos haya llegado de aquellos mundos dispersos en el universo, a través de las voces secretas que oían los magos, y que siguen oyendo los magos-músicos de nuestro tiempo, en el aleteo prodigioso de las notas musicales y el eco de la percusión rítmica de nuestra vida. 